\title{
The diagnostic utility of gram stain microscopy in paediatric septic arthritis - a retrospective case study
}

\author{
J Wong ${ }^{*}$, R Barksfield, R Hutchinson \\ From International Conference for Healthcare and Medical Students 2011 \\ Dublin, Ireland. 4-5 November 2011
}

\section{Introduction}

The diagnosis of septic arthritis in children remains challenging despite reasonable evidence for the use of laboratory tests in diagnosis. There is also limited data on the diagnostic utility of gram stain microscopy in diagnosis. We therefore aim to establish the diagnostic utility of gram stain and predictive clinical and laboratory features of paediatric septic arthritis.

\section{Methods}

We conducted a retrospective review of all patients of 16 years and under that underwent aspiration with or without washout of suspected septic joint from January 2005 to March 2011. Cases were defined as any patient with an organism identified on microbiology culture. The association between clinical features, laboratory results, operative findings and gram stain examination were compared against final culture results with chi-square test (for categorical data) and Mann Whitney test (for nonparametric data).

\section{Results}

Twenty three paediatric patients were identified during the time period, of which 9 (39\%) had positive culture. There was no statistically significant data to show that clinical features or operative findings were predictive of final results. Of the blood test results found, CRP has statistical significant rise ( $\mathrm{p}=0.01$ ) in culture positive (mean 33 , IQR 8-293) septic joints compared to culture negative (mean 107, IQR 65-190) with CRP >65 rendering sensitivity 100\% and specificity $78 \%$. Gram stain microscopy showed $33.3 \%$ sensitivity and $100 \%$ specificity.

Norwich Medical School, University of East Anglia and Norfolk and Norwich University Hospital, UK

\section{Conclusions}

Presenting features, operative findings and most laboratory tests are unhelpful in predicting diagnosis for septic arthritis. However a high CRP (>65) may be useful diagnostic tool proven by high sensitivity. Positive gram stain is strongly predictive of culture positive septic arthritis although diagnosis cannot be excluded on the basis of negative gram stain. Further research should be conducted using CRP and gram stain alongside each other as diagnostic utility for paediatric septic arthritis as demonstrated by the research.

Published: 9 July 2012

doi:10.1186/1753-6561-6-S4-P35

Cite this article as: Wong et al:: The diagnostic utility of gram stain microscopy in paediatric septic arthritis - a retrospective case study. BMC Proceedings 2012 6(Suppl 4):P35.
Submit your next manuscript to BioMed Central and take full advantage of:

- Convenient online submission

- Thorough peer review

- No space constraints or color figure charges

- Immediate publication on acceptance

- Inclusion in PubMed, CAS, Scopus and Google Scholar

- Research which is freely available for redistribution
() Biomed Central

\section{() Biomed Central}

